\title{
From Pluripotency to Early Differentiation of Human Embryonic Stem Cell Cultures Evaluated by Electron Microscopy and Immunohistochemistry
}

\author{
Janus Valentin Jacobsen, Claus Yding Andersen, \\ Poul Hyttel and Kjeld Møllgård \\ University of Copenhagen
}

Denmark

\section{Introduction}

Under appropriate culture conditions human embryonic stem cells (hESCs) can retain an undifferentiated state during numerous passages (Thomson et al., 1998). In the undifferentiated state, hESCs express characteristic markers like NANOG, OCT4, TDGF1, DNMT3B, GABRB3, and GDF3, and are maintained by plating undifferentiated cells or colonies of cells into new culture dishes with fresh medium every 7 to $10^{\text {th }}$ day (Adewumi et al., 2007). Following periods exceeding 7 to 10 days in culture without passage, the cell population tends to become heterogeneous with differentiation starting to occur within a given colony or in various parts of a culture dish. The tendency for undergoing differentiation is independent of whether feeder cells, protein matrixes, or special plastic surfaces are used and what specific hESC medium is employed. Although an increasing density of cells during culture has been suggested to be one reason for spontaneous differentiation of cells to occur, it is also well known that morphologically perfect undifferentiated hESCs often appear in very high density in the same culture dish, even when differentiation has started to occur (Laursen et al., 2007). The transition from the undifferentiated state to more differentiated cell types appears to take place as a gradual process in colonies of hESCs, and it is currently not known how the ultrastructural organization of cells changes along with the differentiation process as defined from immunohistochemical differentiation markers. In the present study we have performed a spatiotemporal investigation on the differentiation of hESC colonies by electron microscopical and immunohistochemical approaches.

\section{Materials and methods}

\subsection{Culture of human embryonic stem cell lines LRB008, LRB010 and LRB017}

The hESC lines LRB008, LRB010, and LRB017 were established at the Laboratory of Reproductive Biology, Copenhagen University Hospital from surplus embryos donated by couples undergoing IVF treatment after informed consent. The study was approved by the regional ethical committee of Copenhagen and Frederiksberg Municipalities (permission no. 
KF 01-188/03). Donated embryos that developed to the blastocyst stage, were used to derive hESC lines following isolation of the inner cell mass isolated by manual dissection using hypodermic needles. The zona pellucida was digested by pronase $(1 \mathrm{mg} / \mathrm{mL})$ (SigmaAldrich, P8811), and the inner cell masses (ICMs) were isolated by immunosurgery. The immunosurgery was performed by incubation in rabbit anti-whole serum antibody (SigmaAldrich, H8765) diluted 1:3 in KnockOut Dulbeccos's modified Eagles medium (KO-DMEM) (Invitrogen, 10829-018) for $30 \mathrm{~min}$, followed by three successive washes in KO-DMEM and incubation in guinea pig serum (State Serum Institute, Copenhagen) diluted in 1:5 KODMEM. The ICMs and the derived cell lines were cultured on mitotically inactivated mouse embryonic fibroblast (MEF) cells in hESC medium based on KO-DMEM supplemented with knockout serum replacement (15\% of final concentration), L-glutamine $(2 \mathrm{mmol} / \mathrm{L}), \beta-$ mercaptoethanol (0.1 mmol/L), MEM non-essential aminoacids $(0.1 \mathrm{mmol} / \mathrm{L})$, Penicillin/Streptomycin (50U/g/mL), and basic fibroblast growth factor (bFGF, $4 \mathrm{ng} / \mathrm{mL}$ ). The cells were cultured in a humidified atmosphere consisting of $6 \% \mathrm{CO}_{2}, 7 \% \mathrm{O}_{2}$ and $87 \% \mathrm{~N}_{2}$ at $37^{\circ} \mathrm{C}$. Cell lines were normally passaged onto fresh MEF feeders once a week, when confluence reached around $70-80 \%$. Passage of cells was carried out by mild trypsin treatment $(0.05 \%$ trypsin in EDTA). An exception to MEFs as supportive feeders was the use of mitotically inactivated human foreskin fibroblast $(\mathrm{hFF})$ in experiments where cell lines LRB008 and LRB017 were harvested for scanning electron microscopy (SEM).

\subsection{Parallel sampling of colonies from the same culture dishes}

For optimal concurrency in the collection of material for electron microscopy and immunohistochemistry, the experimental design was based on parallel sampling from the same culture dishes as illustrated in Figure 1. Colonies from the hESC line LRB010 were cultured for a period of either $6,8,11,14$ or 17 days. Samples were pooled in groups of early stage ( 6 and 8 days), intermediate stage (11 and 14 days), and late stage (17 days) colonies, according to duration of cultures at harvest. In addition, colonies of two other hESC lines, LRB008 and LRB017, were cultured and harvested after 7 and 14 days, for immunohistochemistry and investigation of colony surface ultrastructure by scanning electron microscopy (SEM).

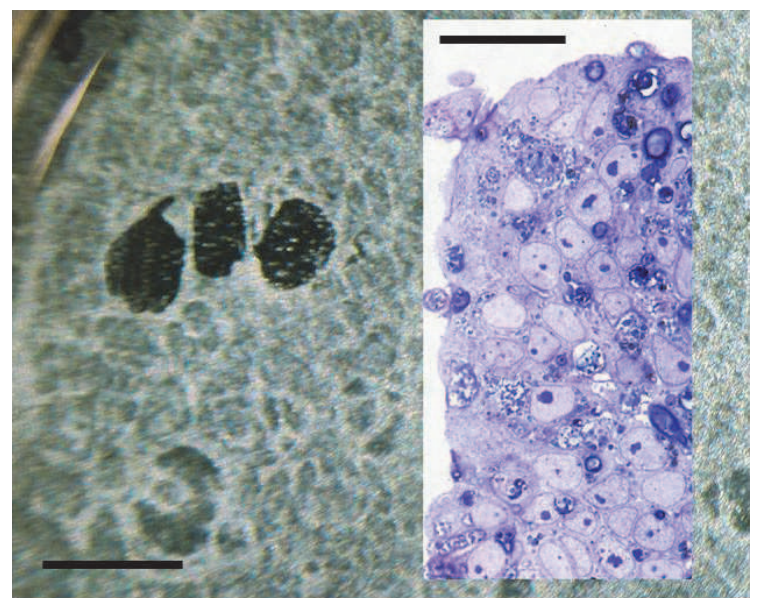

Fig. 1. The principle of parallel sampling. 
The large greyscale phase contrast micrograph shows the bottom of a culture dish with growth of the hESC line LRB010 on a HFF feeder cell layer. Three black holes can be observed next to each other, where hESC colonies have been removed manually by hypodermic needles for fixation in glutaraldehyde and subsequent ultrastructural studies. The light micrograph shown in the inset depicts a semithin survey section $(2 \mu \mathrm{m})$ with part of a fixed colony embedded in epoxy resin and stained with toluidine blue. After removal of tissue samples for electron microscopy, the remaining layer within the culture dish was fixed with Bouin's fixative for immunohistochemistry. Phase contrast micrograph: Scale bar $=5 \mathrm{~mm}$. Light micrograph insert: Scale bar $=25 \mu \mathrm{m}$.

\subsection{Processing of tissue for transmission electron microscopy (TEM)}

Cultured hESC lines were detached using hypodermic needles and fixed in $3 \%$ glutaraldehyde in $0.1 \mathrm{M}$ Na-phosphate buffer $(\mathrm{pH} 7.3)$ for $1-2 \mathrm{~h}$ at $4^{\circ} \mathrm{C}$. Following fixation, specimens were transferred into $0.1 \mathrm{M} \mathrm{Na}$-phosphate buffer $\left(\mathrm{pH} \mathrm{7.3)}\right.$ and stored at $4^{\circ} \mathrm{C}$ for later processing. Specimens were embedded in $4 \%$ agar at $45^{\circ} \mathrm{C}$ (Bacto-agar, Difco Laboratories, Detroit, USA) under stereo microscopy and post-fixed in $1 \% \mathrm{OsO}_{4}$ in $0.1 \mathrm{M}$ Na-phosphate buffer ( $\mathrm{pH}$ 7.3) for $1 \mathrm{~h}$ at room temperature followed by wash in $0.1 \mathrm{M}$ Na-phosphate buffer ( $\mathrm{pH}$ 7.3) for $5 \mathrm{~min}$. Tissue samples were stained en-bloc with $1 \%$ uranyl acetate in MilliQ water (MilliRO Plus and MilliQ PF Plus Water Purifications Systems, Millipore A/S, Hedehusene, Denmark), dehydrated in a series of ascending concentrations of ethanol (50\% for $10 \mathrm{~min}, 70 \%$ for $10 \mathrm{~min}, 96 \%$ for $10 \mathrm{~min}, 99 \%$ for $3 \times 20 \mathrm{~min}$ ). Following the dehydration steps, samples were embedded in Epon (TAAB 812 Embedding resin, Medium), using propylene oxide as an intermedium, and polymerized for $48 \mathrm{~h}$ at $60^{\circ} \mathrm{C}$. Semithin sections $(2 \mu \mathrm{m})$ were cut on an ultramicrotome (Reichert Ultracut UCT, Leica) using glass knifes prepared on a knifemaker (LKB Bromma 7800). Sections were then stained with $1 \%$ basic toluidine blue for evaluation by bright-field light microscopy until a satisfactory part of the colony was exposed. Sections of interest were re-embedded (Hyttel and Madsen, 1987) for further ultrathin sectioning $(70 \mathrm{~nm})$ on an ultramicrotome (Reichert Ultracut UCT, Leica) using a diamond knife (Jumdi, $2 \mathrm{~mm}$ ). The ultrathin sections were contrast stained using $2 \%$ uranyl acetate in MilliQ water and lead citrate (Reynolds, 1963), collected on 150 mesh copper grids covered with a parlodion/amylacetate film, and examined using a transmission electron microscope (CM100, Philips, Darmstadt, Netherlands).

\subsection{Processing of tissue for scanning electron microscopy (SEM)}

Cultures of hESCs grown on glass coverslips were fixed in $3 \%$ glutaraldehyde diluted in 0.1 M Na-phosphate buffer ( $\mathrm{pH} 7.3$ ) for approximately $1 \mathrm{~h}$ at $4^{\circ} \mathrm{C}$, then transferred into $0.1 \mathrm{M}$ Na-phosphate buffer $(\mathrm{pH} 7.3)$ and stored at $4^{\circ} \mathrm{C}$. On the day of further processing the specimens were washed $3 \times 5 \mathrm{~min}$ in $0.1 \mathrm{M}$ Na-phosphate buffer ( $\mathrm{pH} 7.3$ ), post-fixed in $1 \%$ $\mathrm{OsO}_{4}$ in $0.1 \mathrm{M}$ Na-phosphate buffer $(\mathrm{pH} 7.2)$ followed by additional $3 \times 5$ min washings in 0.1 M Na-phosphate buffer ( $\mathrm{pH}$ 7.3). Glass coverslips with hESC colonies were then transferred from plastic growth plates into glass dishes and dehydrated in a series of ascending concentrations of acetone ( $25 \%$ for $10 \mathrm{~min}, 40 \%$ for $10 \mathrm{~min}, 60 \%$ for $10 \mathrm{~min}, 75 \%$ for $10 \mathrm{~min}$, $90 \%$ for $10 \mathrm{~min}, 100 \%$ for $3 \times 20 \mathrm{~min}$ ). Glass coverslips with colonies were too large to fit into chambers of the critical point dryer and therefore had to be fractioned into smaller pieces under stereo microscope. The intermediate fluid acetone, was eliminated from the cells using a critical point dryer (EMS850, Electron Microscopy Sciences, Hatfield, Pennsylvania, 
USA) by several flushings with liquid $\mathrm{CO}_{2}$. Subsequently, critical point drying was performed. Pieces of coverslips with dried colonies were then mounted on specimen holders and coated with $5 \mathrm{~nm}$ gold/palladium in a sputter coater (SC7640 Suto/Manual High Resolution Sputter Coater, Quorum Technologies, Newhaven, UK). Specimens were evaluated using a scanning electron microscope (FEI Quanta 200, FEI Company, Eindhoven, The Netherlands).

\subsection{Processing of tissue for immunohistochemistry}

Colonies of the three hESC lines (LRB008, LRB010 and LRB017) were cultured under conditions as described above for 6, 7, 8, 11, 14 and 17 days and fixed in Bouin's fixative in situ in the culture dish following removal of material intended for electron microscopy. After 1 to 2 hours of fixation the fixative was replaced with $70 \%$ ethanol and $24-48$ hours later the $70 \%$ ethanol was replaced with $90 \%$ ethanol. Following overnight dehydration in $90 \%$ ethanol, the samples were exposed to $99 \%$ ethanol for 12 hours. Then the colonies were gently dissected free from the bottom using a Cell Scraper (Nunc) starting from the periphery. Colonies were then lifted carefully from the bottom of the culture dish to a small metal embedding mould into which xylene was pipetted. After 1 hour's exposure to xylene, paraffin was gently added to the embedding mould. Following paraffin embedding specimens were cut in 3-5 $\mu \mathrm{m}$ thick serial horizontal sections, strictly in parallel to the bottom of the cultures (Brøchner et al., 2010). Every $10^{\text {th }}$ section was stained by toluidine blue.

Prior to immunohistochemistry, non-specific binding was inhibited by incubation for 30 minutes with blocking buffer (ChemMate antibody diluent S2022, DakoCytomation, Glostrup, Denmark) at room temperature. The sections were incubated overnight at $4^{\circ} \mathrm{C}$ with rabbit polyclonal or mouse monoclonal antibodies against OCT4, occludin, ZO-1, claudin-5, $\beta$ catenin, E-cadherin, N-cadherin, vimentin and nestin (details in Table 1). The sections were then washed with TBS and incubated for 30 minutes with the REAL EnVision ${ }^{\mathrm{TM}}$ Detection System, Peroxidase/DAB+, Rabbit/Mouse, (K5007) from DakoCytomation. The sections were counterstained with Mayer's hematoxylin and dehydrated in graded alcohols followed by xylene and coverslipped with DPX mounting media. Control sections were incubated with mouse IgG1, IgG2a or irrelevant rabbit antibodies, as well as subjected to omission of primary or secondary antibodies. Regarding OCT4, preincubation was performed 1 hour before incubation with the corresponding peptide in the proportion 1 to 5 .

\begin{tabular}{|l|c|c|c|c|c|}
\hline \multicolumn{1}{c}{ Antigen } & Manufacturer & Code nr. & \multicolumn{2}{c|}{ Antibody-species } \\
\hline$\beta$-catenin & TriChem & $17 C 2$ & $\begin{array}{c}\text { Mouse } \\
\text { IgG2a }\end{array}$ & $\div$ & $1: 1000$ \\
\hline Claudin-5 & Abcam & Ab 5106 & Rabbit & M6 & $1: 100$ \\
\hline E-cadherin & Abcam & Ab1416 & Rabbit & M6 & $1: 50$ \\
\hline N-cadherin & Abcam & Ab12221 & Rabbit & M6 & $1: 500$ \\
\hline Nestin & Chemicon & MAB 5326 & $\begin{array}{c}\text { Mouse, } \\
\text { IgG1 }\end{array}$ & $\div$ & $1: 500$ \\
\hline Occludin & Abcam & Ab64482 & Rabbit & M6 & $1: 75$ \\
\hline OCT4 & Abcam & Ab 19857 & Rabbit & TEG & $1: 400$ \\
\hline Vimentin & Dako & M0725 & Mouse & M6 & $1: 100$ \\
\hline ZO-1 & Zymed & Z-R1 & Rabbit & $\div$ & $1: 400$ \\
\hline
\end{tabular}

Table 1. Primary antibodies, manufactures, code numbers and dilutions. 


\section{Results}

The cells and colonies grown on MEF feeders or hFF feeders in a culture medium with bFGF added developed well, with a typical morphology of undifferentiated stem cells showing areas of large single nucleated cells with scanty cytoplasm interspersed with cells of more differentiated morphology depending on culture age.

\subsection{Transmission electron microscopy}

Early stage colonies: In $2 \mu \mathrm{m}$ survey sections from Epon-embedded material, the colonies appeared multi-layered with the highest numbers of cell layers in the center, flattening towards the periphery. Three different cell compartments within the colony were chosen for closer ultrastructural examinations, as illustrated by rectangles in Fig. 2, and consisted of: 1) an apical compartment with cells facing the culture medium; 2) a basal compartment containing cells anchoring the colony to the feeder cell layer, and; 3 ) a compartment in the center of the colony demarcated by apical and basal cells. In the apical compartment (Fig. 2C-E), cells were polarized with a large apical cytoplasm, rich in organelles, and nuclei located basally. Cells were connected to each other by apical junctional complexes - zonulae occludentes (tight junctions) and zonulae adherentes (adherens junctions), with abundant association of intermediary filaments of the cytoskeleton. Microvilli were observed projecting from the cell surfaces. Below the apical epithelial covering of the colony, a population of cells with a large nucleus to cytoplasm ratio and poor in organelles, representing a typical undifferentiated ESC-like morphology, resided in the center of the colony (Fig. 2B). Cell membranes of the basal cell compartment did not show any sign of junctional specializations, and higher magnification confirmed a continuous even spacing between the plasma membranes of the basal cells (Fig. 2F and G).

Intermediate stage colonies: The $2 \mu \mathrm{m}$ survey sections showed a colony thickness of one or few cell layers. The colony harvested the $11^{\text {th }}$ day of culture was still attached to a monolayer of MEF feeder cells with a distinct basement membrane separating them. Towards the apical surfaces, well developed tight and adherens junctions at the lateral plasma membrane connected cells of the apical compartment. Below the junctional complex, well-developed gap junctions and maculae adherentes (desmosomes) could be observed. All junctional complexes were closely associated with extensive bundles of intermediate filaments (Fig. 3C-D and 4D). In basal regions, adjacent cells were interdigitating and showed many gap junctions, whereas tight junctions, adherens junctions, and desmosomes were lacking (Figs. $3 \mathrm{~A}, \mathrm{~B}, \mathrm{E} \& \mathrm{~F}$ and $4 \mathrm{~A}, \mathrm{~B}, \mathrm{C} \& \mathrm{E})$.

Late stage colonies: In $2 \mu \mathrm{m}$ survey sections, basal and center compartments were easily identified. Remnants of the basement membrane, but no feeder cells, were observed beneath the basal cells of the colony (Fig. 5A). The apical compartment contained a population of cells with obvious epithelial specializations such as junctional complexes with associated desmosomes, polarized organelle rich cytoplasm with basally located nuclei, and microvilli covering the apical surfaces. As was the case for early and intermediate stage colonies, a network of intermediary filaments radiated from sites of junctional complexes, where gap junctions were also present (Fig. 5C-E). At this late stage, a population of cells with ESC-like undifferentiated morphology similar to the ones previously described was still present (Fig. 5B).

Specializations linking adjacent plasma membranes of the basal compartment apart from obvious gap junctions were not observed (Fig. 5F-G). 

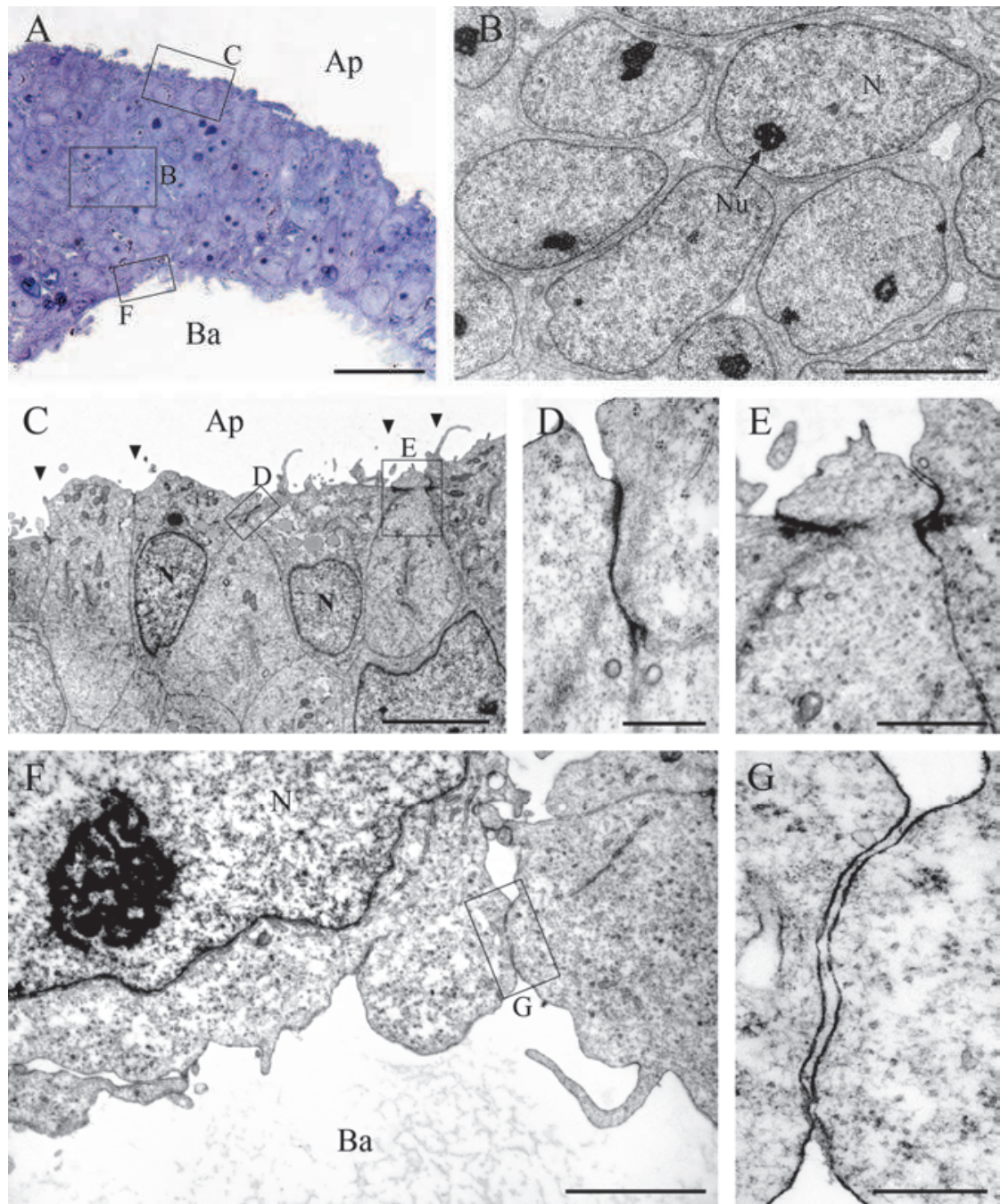

Fig. 2. Transmission electron micrographs of hESC line LRB010 cultured for 6 days (early).

(A) Semithin cross section illustrating 3 different spatial compartments within the colony: Upper rectangle represents the localization of an apical compartment facing the culture medium in vitro, lower rectangle illustrates a population of basal cells anchoring the colony to the feeders, and the rectangle in the centre represents cells in between the apical and the basal compartment. Stained with toluidine blue. Ap, apical; Ba, basal. Scale bar $=25 \mu \mathrm{m}$. (B) Representative area from the center compartment with cells of typical undifferentiated morphology. N, nucleus; $\mathrm{Nu}$, nucleolus. Scale bar $=5 \mu \mathrm{m}$. (C) Apical region of the colony with tight junction specializations shown in inserts. Scale bar $=5 \mu \mathrm{m}$. (D) Tight junction complex from insert in C (left). Scale bar $=500 \mathrm{~nm}$. (E) Tight junctions from inset in C (right). Scale bar $=1 \mu \mathrm{m}$. (F) Basal region of the colony with a representative junction framed. Scale bar $=2 \mu \mathrm{m}$. (G) High magnification of inset in $(F)$ showing no signs of junction specializations. Scale bar $=250 \mathrm{~nm}$. 

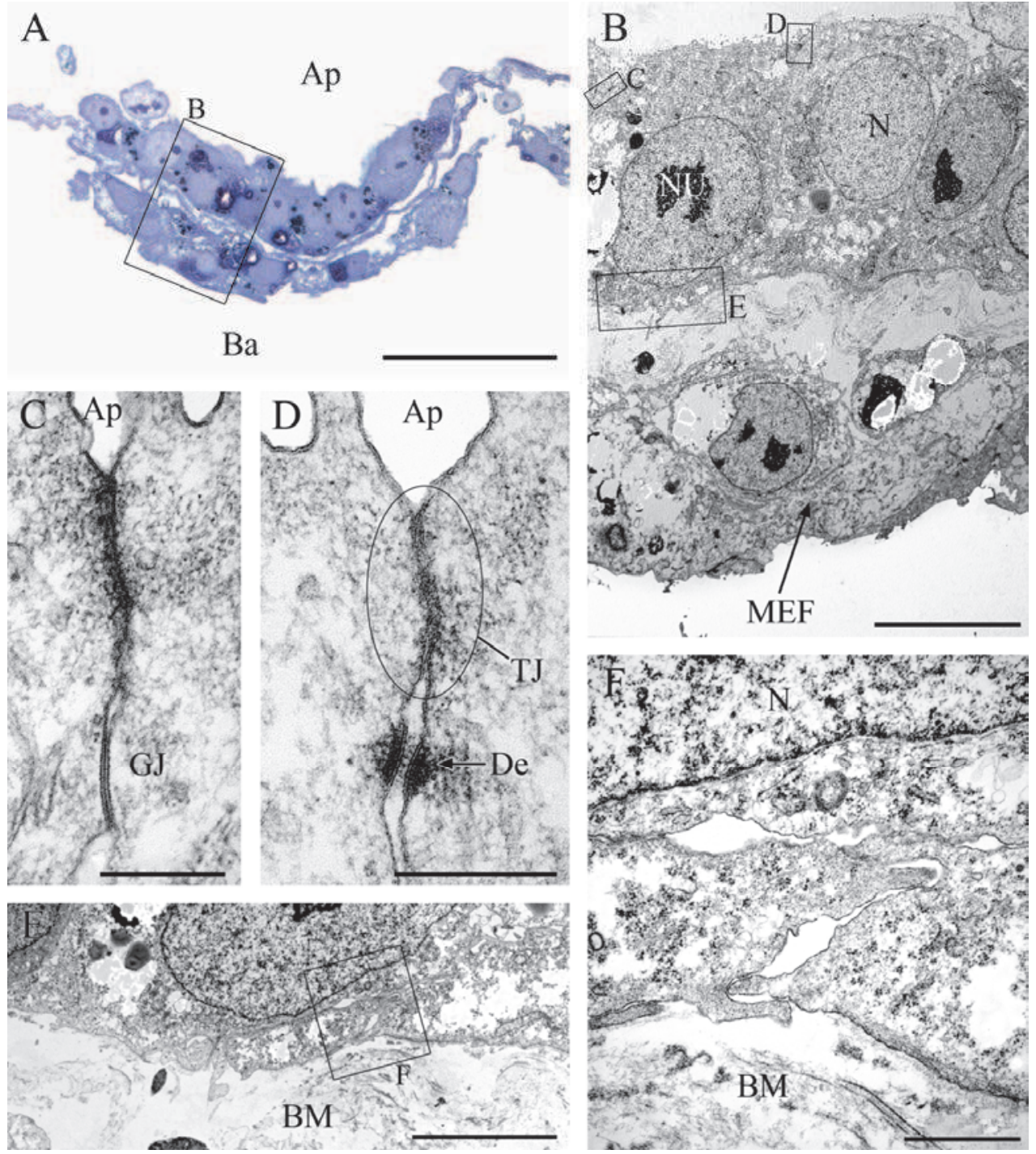

Fig. 3. Transmission electron micrographs of hESC line LRB010 cultured for 11 days (intermediate).

(A) Light microscopy of semithin cross section of colony with framed area spanning the apical and basal compartments magnified in B-F. Ap, apical; Ba, basal. Scale bar $=50 \mu \mathrm{m}$. (B) Apical and basal regions further magnified are framed. MEF, mouse embryonic fibroblast feeder layer; N, nucleus; $\mathrm{Nu}$, nucleolus. Scale bar $=10 \mu \mathrm{m}$. (C) Junctional complex with distinct gap junction (GJ). Scale bar $=250 \mathrm{~nm}$. (D) Tight- and adherens junction (TJ) with associated desmosome (De). Scale bar $=250 \mathrm{~nm}$. (E) Basal region showing interdigitating processess without junctional specializations. BM, basement membrane. Scale bar $=10 \mu \mathrm{m}$. (F) Higher magnification of insert in E. Scale bar $=1 \mu \mathrm{m}$. 

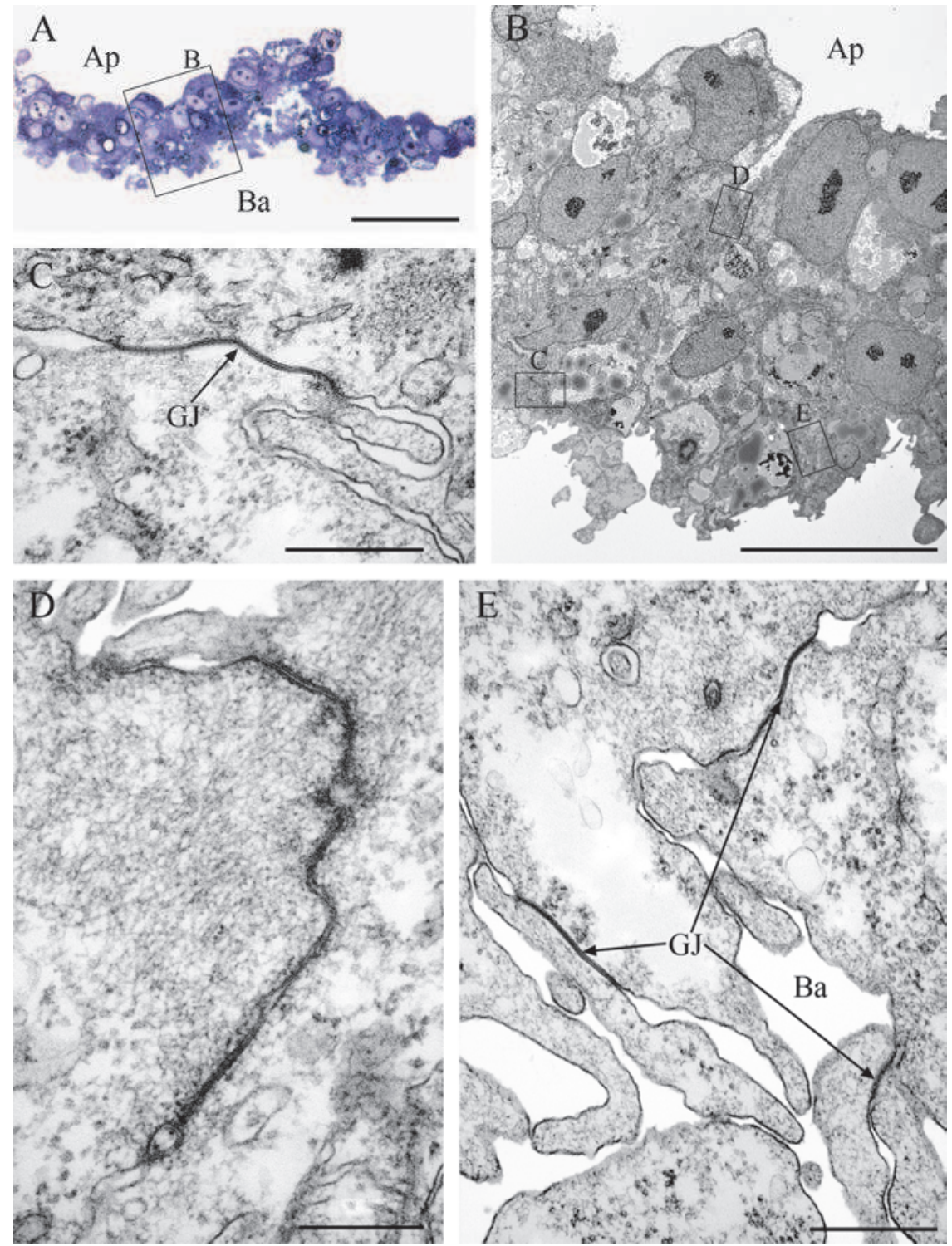

Fig. 4. Transmission electron micrographs of hESC line LRB010 cultured for 14 days (intermediate).

(A) Light microscopy of semithin cross section of colony marking representative area (frame) chosen for further analysis. Ap, apical; Ba, basal. Scale bar $=50 \mu \mathrm{m}$. (B) Marked locations (frame) of junctional areas seen in (C-E). BM, basement membrane. Scale bar $=20 \mu \mathrm{m}$. (C) Gap junction (GJ) in connection to inderdigitations in the basal region of the colony. Scale bar $=500$ nm. (D) Tight- and adherens junction with prominent intermediary filament cytoskeleton. Scale bar $=250 \mathrm{~nm}$. (E) Abundant gap junctions (GJ) at the basal region. Scale bar $=500 \mathrm{~nm}$. 
From Pluripotency to Early Differentiation of Human Embryonic
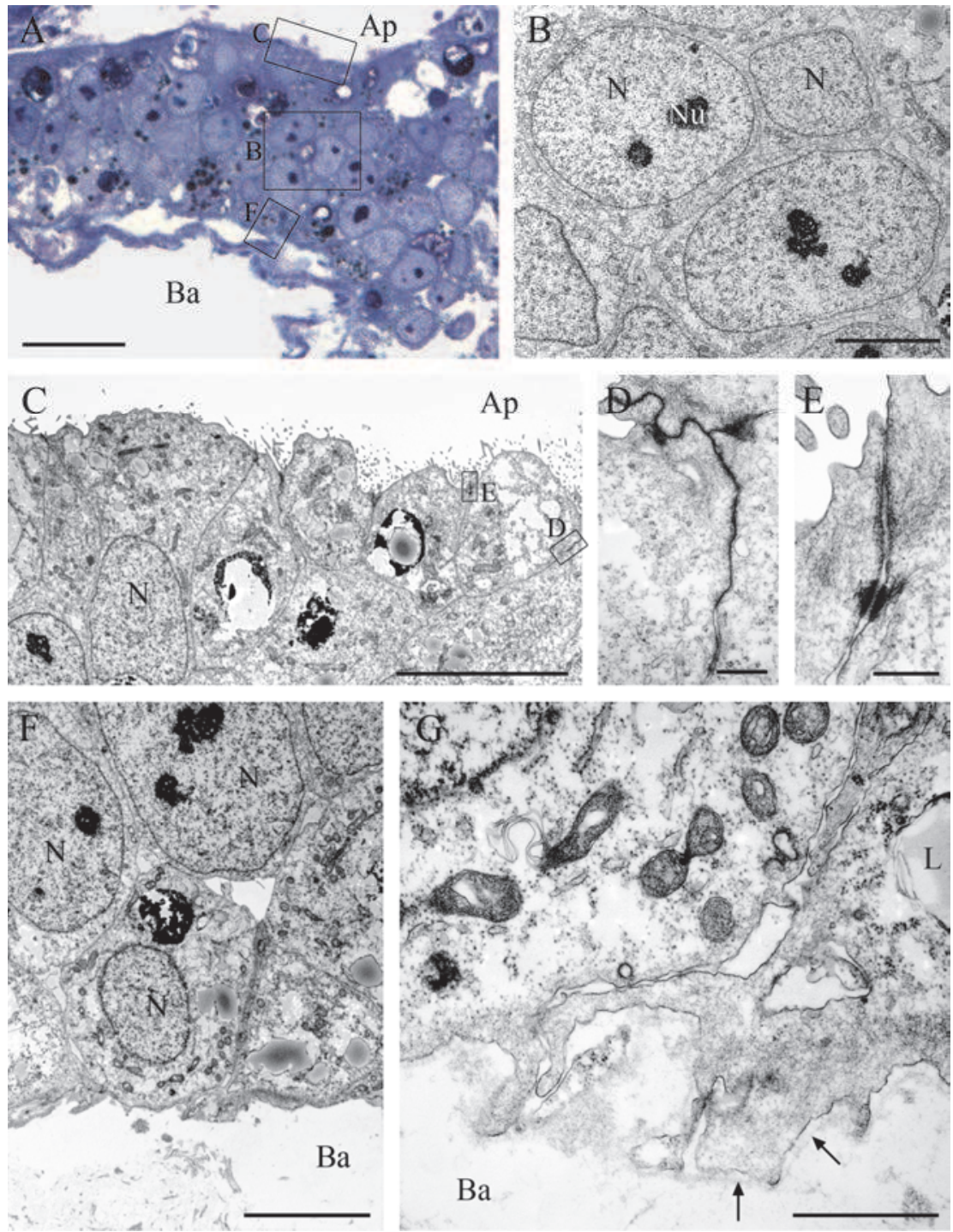

Fig. 5. Transmission electron micrographs of hESC line LRB010 cultured for 17 days (late). (A) Light microscopy of semithin overview section showing areas representative of apical, central and basal compartments of the colony. Ap, apical; Ba, basal. Scale bar $=20 \mu \mathrm{m}$. (B) Central compartment containing cells of typical undifferentiated morphology. $\mathrm{N}$, nucleus. Scale bar $=5 \mu \mathrm{m}$. (C) Apical compartment where top layer of cells are bound together by apical junctional complexes (arrows). Two of the junctions can be seen in D-E. Scale bar $=10$ $\mu \mathrm{m}$. (D) Tight junction (C, left). Scale bar $=500 \mathrm{~nm}$. (E) Tight- and adherens junction (C, right) with distinct desmosome. Scale bar $=250 \mathrm{~nm}$. (F) Basal compartment. Scale bar $=5$ $\mu \mathrm{m}$. (G) Basal region without specializations. Basement membrane is marked by arrows. M, mitochondria; L, lipid droplet. Scale bar $=1 \mu \mathrm{m}$. 


\subsection{Scanning electron microscopy}

Although 7 day-old colonies (LRB008 and LRB017) and feeders presented cracks resulting from the dehydration and critical drying processes, plenty of undamaged colony surface area was available for further examination. At low magnification, the colonies appeared as a flattened sheet of cells with a distinct boundary to the feeder cell layer they were grown on (Fig. 6A-B). The majority of the colony surface consisted of a fairly homogenous, flattened cell layer, but marked differences could be noted between individual cells in the flattened cell layer, with some cells having smooth surfaces, while others appeared with more rough surfaces covered by microvilli (Fig. 6C). Other surface areas displayed a more uniform
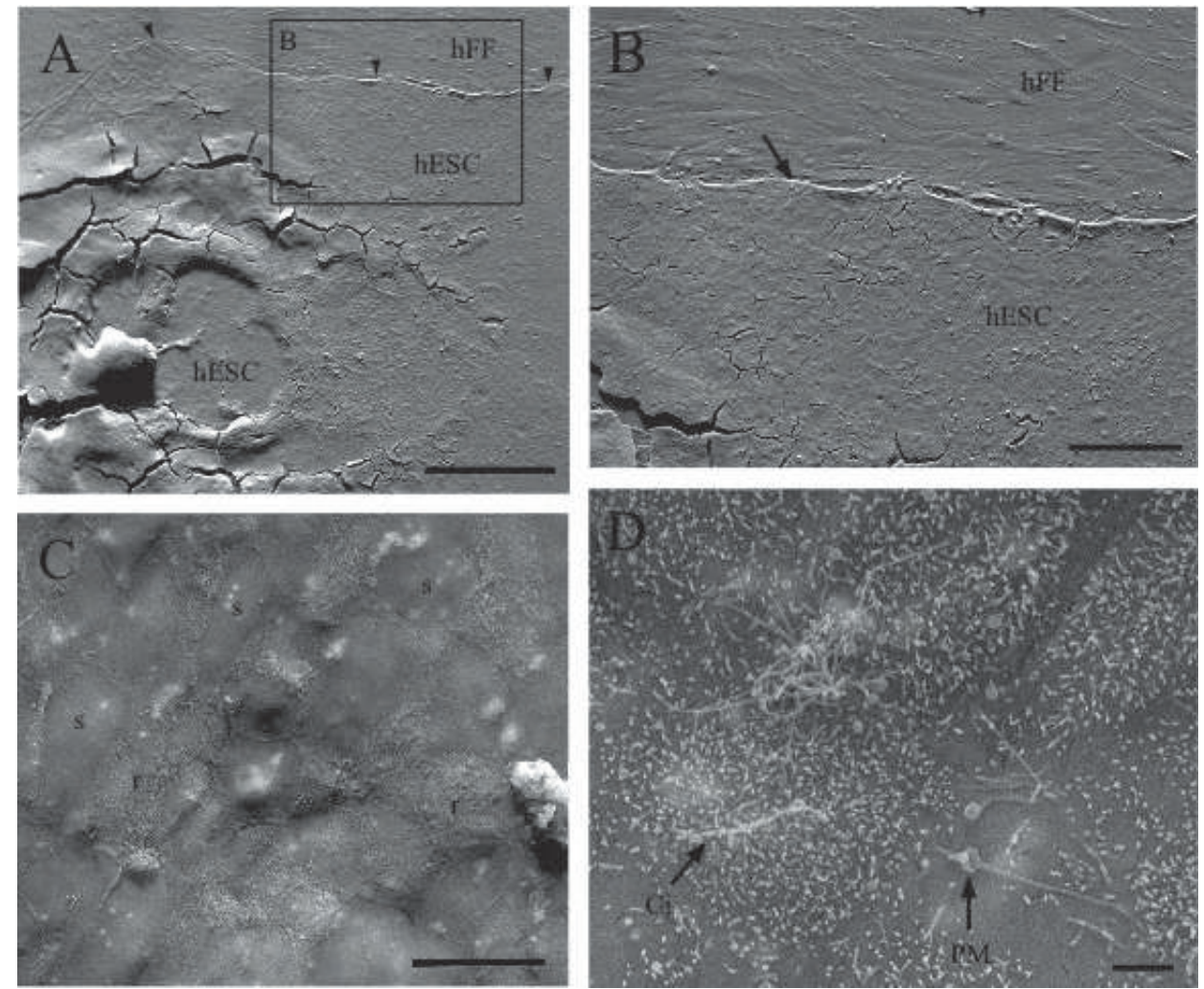

Fig. 6. Scanning electron micrographs of hESC lines LRB008 and LRB017 grown on human foreskin fibroblasts for 7 days in culture.

(A) Colony with arrowheads indicating border between colony and feeder layer. $\mathrm{hFF}$, human foreskin fibroblasts; hESC, human embryonic stem cells. Scale bar $=500 \mu \mathrm{m}$. (B) Inset in (A) showing higher magnification of the periphery with arrow indicating border between colony and feeder layer. Scale bar $=200 \mu \mathrm{m}$. (C) Colony showing marked differences in cell surfaces. Some cells appear smooth surfaced (s), while others have a rougher surface ( $\mathrm{r}$ ) coved by microvillous extensions. Scale bar $=20 \mu \mathrm{m}$. (D) Microvillous surface in the periphery of the colony showing a cilium (Ci) extending from it, and a polar midbody $(\mathrm{PM})$ still connecting dividing daughter cells. Scale bar $=2 \mu \mathrm{m}$. 
distribution of microvilli, and the presence of individual cilia could be documented (Fig. 6D). Commonly, both cell lines exhibited superficial cytoplasmic bridges still connecting dividing daughter cells, with distinct polar midbodies (Fig. 6D).

Low magnification images of the 14 day-old colonies revealed great differences in the overall morphology of the two different cell lines investigated. One colony (LRB008) formed big bulging areas of cells growing in layers into the culture medium, while the other (LRB017) retained the flattened sheet-like appearance even after 14 days in culture (Fig. 7AD). In the bulging areas of LRB008, separate cells clearly grew on top of each other, some forming structures protruding from the surface (Fig. 7A-B). Superficial cytoplasmic bridging between dividing cells was seen in LRB008, but not in LRB017. The rather uniform cell layer of LRB017 occasionally showed rounded protrusions of the plasma membrane, often in clusters (Fig. 7D). Furthermore, a varied microvillous covering could be observed through out the colonies of both cell lines on bulging as well as homogenous flat areas.
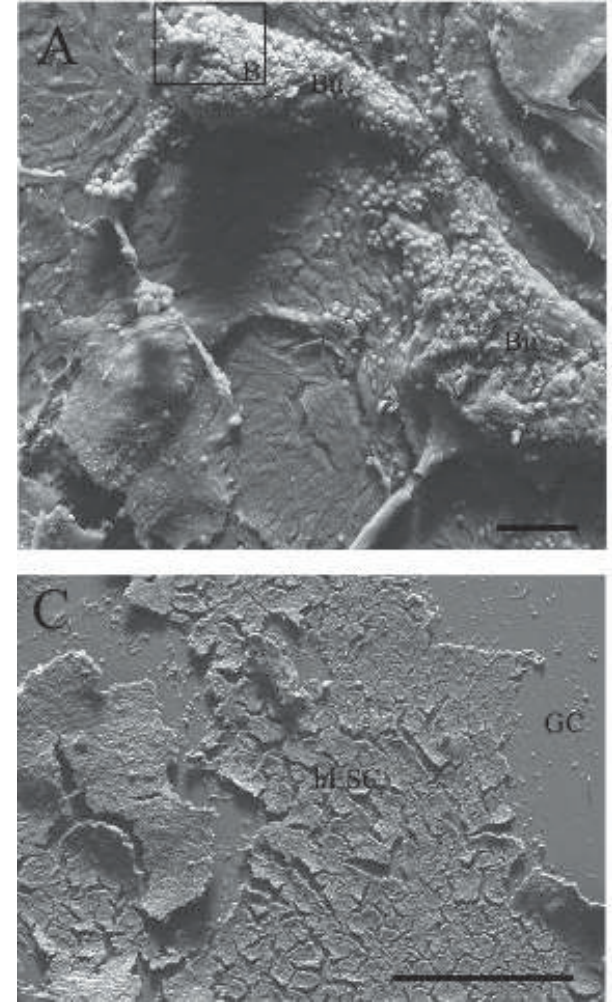
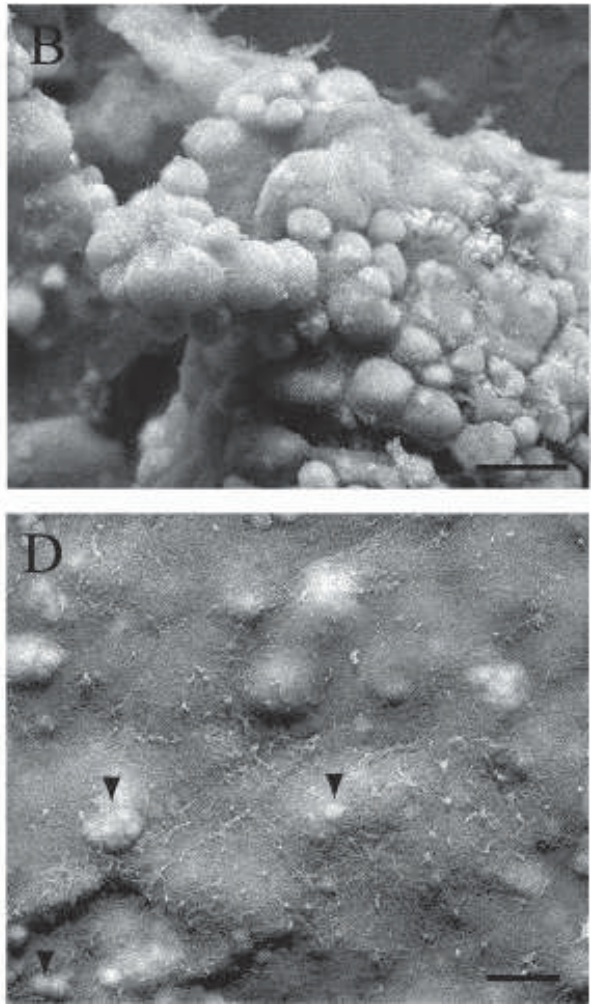

Fig. 7. Scanning electron micrographs of hESC lines LRB008 and LRB017 grown on human foreskin fibroblasts for 14 days in culture.

(A) Bulging $(\mathrm{Bu})$ areas of differentiation on LRB008 after 14 days of culture. Scale bar $=100$ $\mu \mathrm{m}$. (B) Higher magnification of inset in A showing differentiating cells protruding from the surface. Scale bar $=20 \mu \mathrm{m}$. (C) Colony of LRB017 partly detached from the glass coverslip (GC) they were grown on. Scale bar $=400 \mu \mathrm{m}$. (D) Higher magnification of hESCs from (C) with areas of membrane protrusions marked by arrowheads. Scale bar $=5 \mu \mathrm{m}$. 

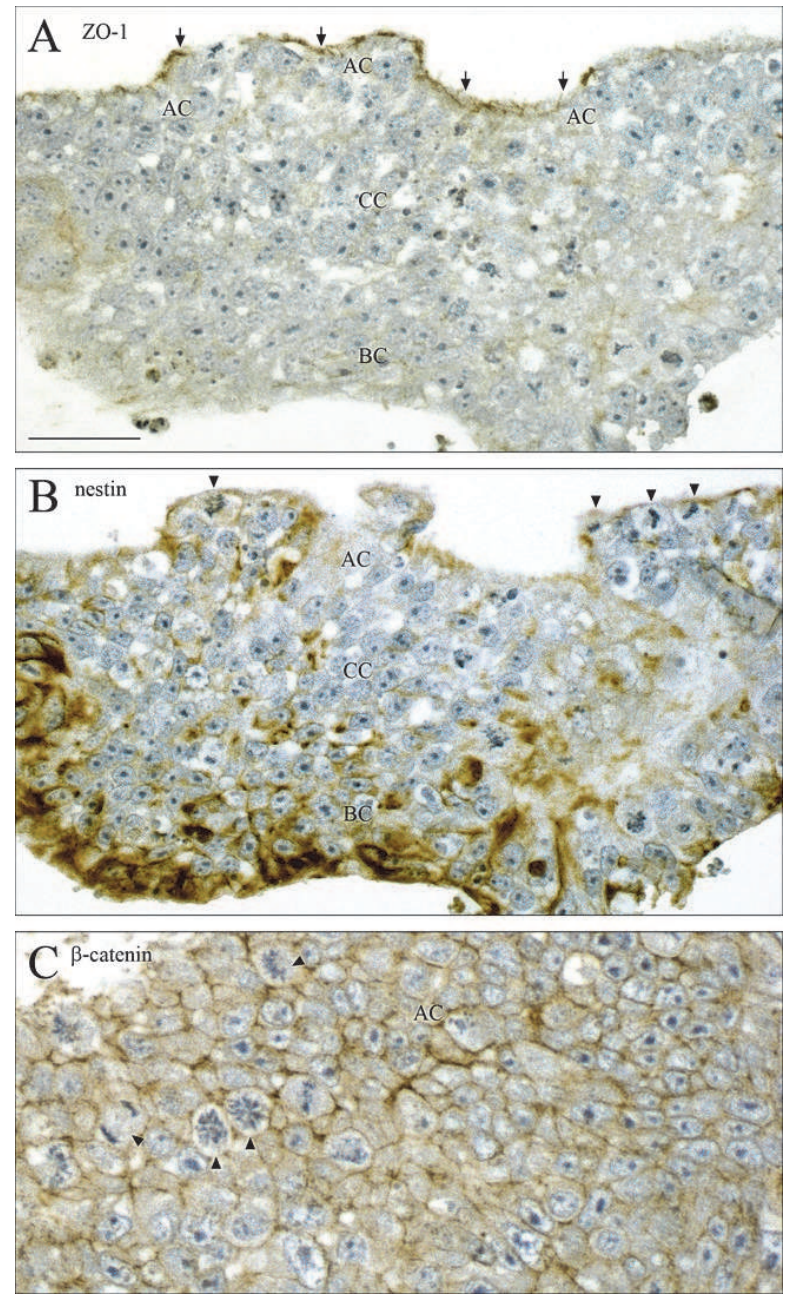

Fig. 8. Expression of ZO-1, nestin and $\beta$-catenin shown by immunohistochemistry in sections from hESC line LRB010 cultured for 6 days.

In (A) stained for ZO-1 the apical compartment (AC) is separated from the culture medium by a tight junctional complex (arrows). The central compartment (CC) and the basal compartment (BC) show no distinct reactivity. (B) The basal compartment (BC) is strongly positive for nestin, whereas the central compartment (CC) is characterized by cells of typical undifferentiated morphology. Note the pattern of differentiation from the center towards the basal compartment indicating a gradual change from hESCs to nestin-positive neuroectodermal cells. Some of the many mitotic figures in the apical compartment (AC) situated at the apical surface facing the culture medium are indicated by arrowheads. (C) A tangential section through the apical compartment $(\mathrm{AC})$ illustrates the strong $\beta$-cateninreactivity associated with the adherens junctions. Note the many mitotic figures (arrowheads), which are also seen in the same region in cross-sectioned colonies (arrowheads in B). A, B \& C: same magnification. Scale bar $=25 \mu \mathrm{m}$. 

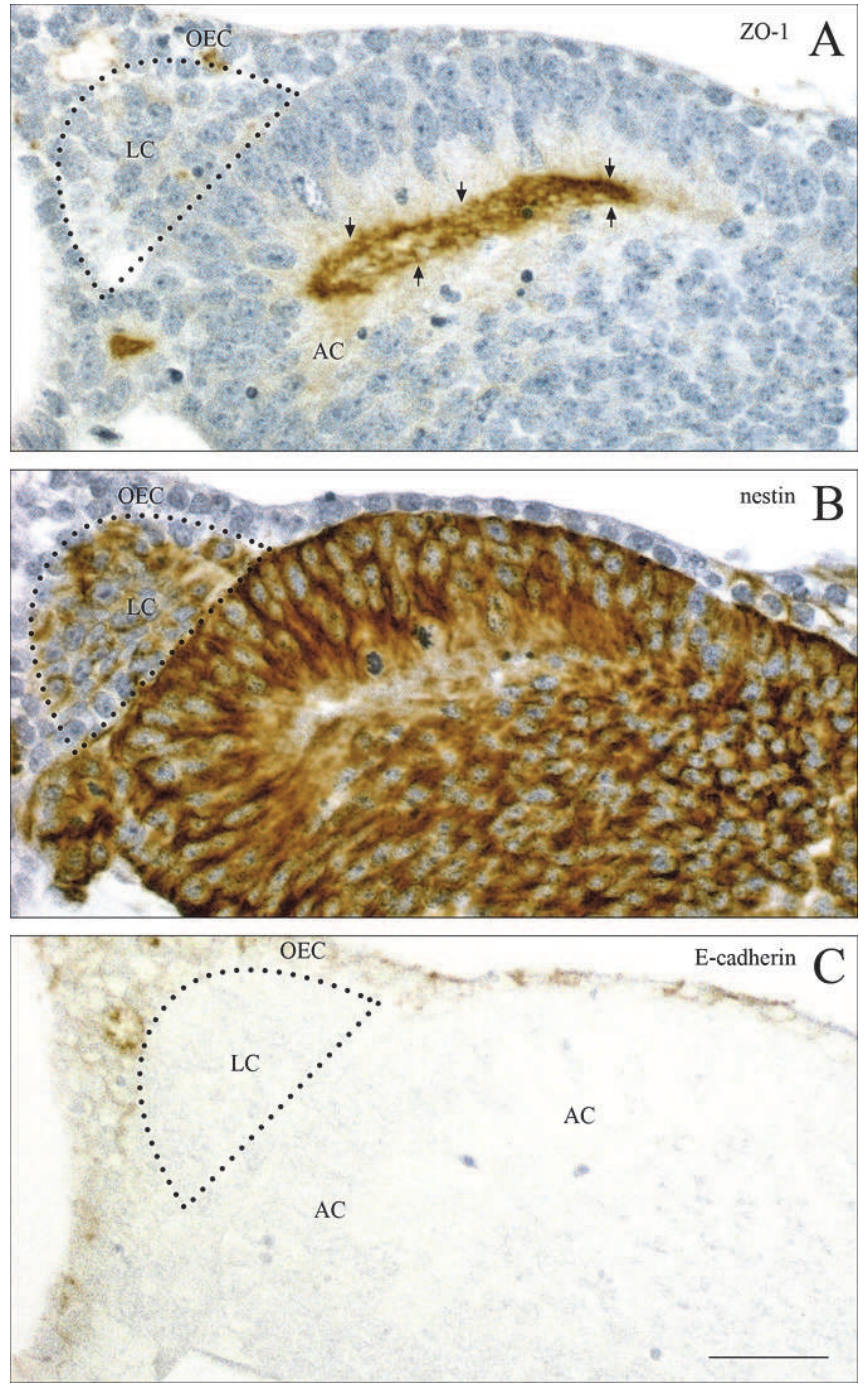

Fig. 9. Expression of ZO-1, nestin and E-cadherin shown by immunohistochemistry in tangential sections from hESC line LRB010 cultured for 17 days.

(A): The apical compartment (AC) in the center of the figure, stained for $\mathrm{ZO}-1$ shows a welldeveloped tight junctional complex (arrows). A lateral compartment (LC) marked by a punctuated line and an outer epithelial compartment (OEC) are not stained. (B) The entire pseudo-stratified epithelium of the apical compartment is strongly positive for nestin. A new lateral compartment (LC) marked by a punctuated line is slightly positive for nestin, but strongly positive for vimentin and N-cadherin (not shown). (C) A single-layered outer epithelial compartment (OEC) and its extension towards the upper left of the figure show positive reactivity for E-cadherin, whereas both apical (AC) and lateral compartments (LC) are unstained. A,B \& C: same magnification. Scale bar $=25 \mu \mathrm{m}$. 


\subsection{Immunohistochemistry}

It was possible to distinguish three different compartments in most colonies already from day 6: (1) An apical epithelial-like polarized layer facing the culture medium; (2) a basal cell layer facing the feeder cell layer; and (3) a central compartment enclosed by the apical and basal cell layers consisting of 'classical' hESCs with 'undifferentiated morphology' (Fig. 8 A$B$ ). The youngest colony showed the presence of markers for tight junctions (occludin, claudin-5 and ZO-1 - Fig. 8A), and adherens junctions (E-cadherin associated with $\beta$-catenin - Fig. 8C) in the apical polarized epithelial-like cell layer. This was in marked contrast to the epithelioid 'classical' hESCs of the central compartment characterized by absence of markers for tight junctions. All cells exhibited positive OCT4-staining of their nuclei pointing to heterogeneity of the early hESCs, i.e. an epithelial-like cell type with junctional complexes facing the outside compartment (the culture medium) and an epithelioid cell type without classical junctional complexes, but with strong OCT4 reactivity in their nuclei. The basal cell layer, on the other hand, exhibited a distinct reactivity for the neuroectodermal marker nestin (Fig. 8B), but markers for tight junctions were absent. A gradual change in the pattern of differentiation from a nestin-negative, but OCT4-positive central compartment towards a strongly nestin-positive basal compartment indicating a gradual change from an OCT4positive hESC population to a neuroectodermal cell population existed as illustrated in Fig. 8 B.

In older colonies (17 days) immunohistochemical analysis revealed that the majority of the differentiating cells had lost their OCT4-positivity, indicating that the central compartment with 'classical' hESCs showing 'undifferentiated morphology' had disappeared in most colonies. An apical epithelial-like pseudostratified layer facing the culture medium was still present. The apical regions of the lateral cell membranes were joined by tight junctions as shown by a positive reactivity for occludin, claudin-5, and ZO-1 (Fig. 9A). In some cases the entire apical layer was densely stained for nestin (Fig. 9B), whereas the apical regions of other colonies showed a very strong staining for vimentin with some more basally located nestin-positive cells (not shown). A single layered outer compartment was characterized by a lack of staining for vimentin and nestin but by a positive staining reaction for E-cadherin (Fig. 9C). In a newly developed lateral compartment adjacent to the apical and above the central compartment cells showed a strongly positive N-cadherin and vimentin-staining but no staining for E-cadherin (Fig. 9C) suggesting an epithelial-mesenchymal transition (EMT) resulting in migratory vimentin-positive mesenchymal-like cells.

\section{Discussion}

Although living hESCs often appear homogenously undifferentiated in their colony formation, as observed in phase contrast microscopy, the present study demonstrates that various differentiation events occur already within a few days after passage both at the ultrastructural and light microscopic level. Usually it is sufficient to maintain hESCs in an undifferentiated state by a passage of cells every 5-7 days. However, here we demonstrate that already within the early stage colonies, around the time of normal passage, a pronounced compartmentalization has taken place within colonies, suggesting spatial and temporal dimensions of differentiation. In all colonies examined, irrespective of the culture period and spatial configuration of the colony, the apical layer of cells, which is in direct 
contact with the culture medium, formed an apico-basolateral polarized sheet of tightly interconnected cells resembling a columnar epithelium and thus providing solid documentation for a morphological specialization linking adjacent cells by junctional complexes consisting of tight and adherens junctions, shown by EM and immunohistochemistry. Such an epithelial coating, forming a barrier to the external environment, might provide deeper lying cells with a selective transcellular uptake of nutrients and other media components, thus creating a microenvironment supporting the undifferentiated state. A central compartment, containing cells with typical undifferentiated ESC-morphology, was indeed observed with EM and immunohistochemistry in both early and medium stage colonies, indicating long-term retention of an environment permissive of undifferentiated cell growth, regardless of surrounding peripheral differentiation. Indeed these observations might also explain why morphological undifferentiated hESC in culture dishes that has been grown for a prolonged period of time of perhaps two weeks or more is often found in the central and basal compartments which are in direct contact with bottom of the culture dish without tight junctions underneath layers of more differentiated cells on top of the colony.

Based upon studies of short-term feeder free cultures, Ullmann et al. (2007) proposed a colony structure almost identical to the early stage colony in this study. The immunostainings for E-cadherin, a marker for epithelial adherens junctions, were localized only to the uppermost cell layer of a multilayer, whereas it disappeared peripherally, where vimentin positive cells began to appear. This provides evidence for an epithelialmesenchymal transition (EMT) in the peripheral regions where the colonies flattens into a monolayer. However, according to our TEM investigations, these peripheral monolayers of the intermediate stage colonies grown on MEF exhibited junctional complexes, hence suggesting an epithelial nature.

Colonies organized with confined undifferentiated cells and peripheral differentiation was confirmed by a shift in immunoreactivity from the pluripotency marker SSEA-4 to a marker of differentiation SSEA-1 towards the periphery (Johkura et al., 2004). This downregulation in pluripotency markers was to some extent also indicated in the short-term feeder free cultures referred to above, where the intensity in immunostainings of the key pluripotency markers OCT4 and NANOG decreased in peripheral regions (Ullmann et al., 2007). Despite an apparent decrease in the amount of the key transcription factors, expression levels were still substantial, raising the question whether a deviation from the undifferentiated morphology to a more epithelial-like morphology is accompanied by decrease in potency. Additionally, increased amounts of laminin in the periphery of the colonies confirmed accumulation of extracellular matrices under standard culture conditions (Johkura et al., 2004), most likely as a constituent of the basement membrane secreted by differentiated epithelial cells. One of the intermediate (11 days in culture) and the late stage colonies had distinct basement membranes. The basement membrane of the intermediate stage colony harvested at the $14^{\text {th }}$ day of culture was supposedly teared of at harvest. This was indicated by the damaged appearance basally. Neither did our observations indicate presence of a basement membrane beneath the most basal cells of the multilayered early stage colony, possibly explaining colony detachment from feeders without damaging structures of the basal cell layer or lifting up accompanying feeders. The location of the basement membrane in the late stage colony (Fig. 5), with its 
multilayered appearance, suggests that it could be a single-cell layer cut in a transverse section deviating somewhat from the perpendicular plane, thus increasing the interface of the section. On the other hand, a model of a multilayered colony consisting of several layered compartments cannot be excluded.

Gap junctions were identified both as part of the apical junctional complex (Fig. 4D), spanning all stages, but also in basal regions of the presumed monolayer in one of the intermediate stage colonies (Fig. 4E). A definite cell-to-cell coupling is demonstrated between epithelial cells of the apical compartment of murine cells of the ICM which are connected to each other (Lo \& Gilula, 1979). The present study suggests that this also may apply to human ICMs. In accordance, Sathananthan et al. (2002) points out that a high degree of ultrastructural similarity exists between cells of the ICM and hESCs with undifferentiated morphology. Hence a gap junctional coupling could be expected between cells within the compartment of cells with undifferentiated morphology. Indeed, gap junctions were found by TEM within the undifferentiated compartment (micrographs not included), also demonstrating cell-to-cell coupling to exist between these cells. Whether the apical epithelial compartment is gap junctionally coupled to the underlying cells with undifferentiated morphology remains to be determined. Differentiation processes are normally associated with the progressive loss of communication between different tissues, for example as observed in between the ICM and the trophectoderm (Lo \& Gilula, 1979). This suggests the possibility of two separate compartments intra-connected by gap junctions without coupling to each other. Huettner et al. (2006) demonstrated extensive gap junction communication in hESC colonies by dye injections and physiological recordings together with documentation of different connexins by immunocytochemistry and RT-PCR, assuming colonies to consist of uniform monolayers of undifferentiated cells corresponding to apical epithelial cells.

In order to document possible differences among different hESC lines, two other cell lines, LRB008 and LRB017, were included to improve our knowledge about the general colony outline and surface structures from a SEM point of view. At least after 7 days, this analysis confirmed that the periphery is composed of a primarily homogenous flat monolayer comparable to single-cell layers visualised by TEM. Cell line LRB017 showed a distinct accumulation of cells in the center of the colony. This was more difficult to identify in cell line LRB008, because the area in question had suffered considerable damage from processing of the sample, which in itself could indicate a thicker cell layer more vulnerable to shrinkage during dehydration. These observations agreed very well with the previously proposed colony structure described by Ullmann et al. (2007), but contradicted the saucershaped colony structure described by Sathananthan et al. (2002), in spite of identical culture conditions and time of harvest for the latter. The impact of duration of cultures is well illustrated by the 14-day old cultures. These showed a more chaotic growth of differentiating cells protruding from the surface in a highly irregular pattern in LRB008 (Fig. 7A-B), while LRB017 maintained a flattened growth. Single or clustered rounded protrusions in the cell membrane, in particular the 14-day-old cultures (Fig. 7D), showed similarity to the coarse particles and halos previously identified by phase contrast microscopy consisting of apoptotic cells and bodies (Johkura et al., 2004). This suggests a pronounced cell death at this late stage. The fact that the entire colonies, in general, were 
covered with microvilli with varying heterogeneity, and often with microvilli-free cells interspersed, suggests that the extent of epithelial specialization of the medium-facing cell layer. Heterogenous cell surfaces between groups of cells, as well as between single adjacent cells, very well correspond to results from a study demonstrating regional differences in expression of specific markers for hESCs (Laursen et al., 2007). Recently, one group published findings of primary cilia on surfaces of 33 and 90 percent of the hESCs of two different cell lines, H1 and LRB003, respectively (Kiprilov et al., 2008). Additionally, cilia were shown to co-localize with OCT4 staining, thus indicating their pluripotency with the assumption of the associated hedgehog signalling machinery to be important in the maintenance of the undifferentiated/self-renewable state. Following 7 days in culture, with the same culture conditions and using two other hESC lines derived also derived in our laboratory, only one single cilium was found. This raises the question of importance of cilia in regulation of hESCs as proposed by Kiprilov et al. (2008), and definitely demonstrates differences among hESC lines.

To EMT, or not to EMT - in vivo and in culture. During in vivo embryogenesis and organ development the process initially termed epithelial-mesenchymal transformation (Hay, 2005), now referred to as epithelial-mesenchymal transition (EMT), (Kalluri \& Weinberg, 2009; Thiery et al., 2009) is a key event. EMT is a biological process that allows an epithelial cell to undergo multiple biochemical changes that enable it to assume a mesenchymal cell phenotype, which includes enhanced migratory capacity, invasiveness, elevated resistance to apoptosis, and increased production of extracellular matrix components (Kalluri and Weinberg, 2009). Early in the third week of human embryonic development, epiblast cells lateral to the primitive streak begin to move into the streak, where they undergo an EMT, i.e. the epithelial epiblast cells elongate and detach from their neighbours and then migrate away below the primitive streak as individual loosely organized mesendodermal progenitors. This process of gastrulation represents the first EMT after implantation (Thiery et al., 2009). After gastrulation the remaining epithelial epiblast cells, which did not enter the primitive streak and therefore did not undergo the initial EMT, form epidermal and neural territories progressively along the rostrocaudal axis. The differentiating neural plate is flanked by the prospective neural crest and further laterally by the prospective surface ectoderm, which constitutes the remaining areas of the ectoderm. Neural crest cells from the neural crest territory in the dorsal neural tube then delaminate in a process of primary EMT (Thiery et al., 2009). However, what has not really been emphasized so far, is the lack of EMT in the initial differentiation of epiblast cells directly into the remaining ecto- and neuroectodermal germ layer - an in vivo process of Epiblast-ectodermal transformation (EET) corresponding to an in vitro process of ESC-ectodermal transformation.

In a previous in vitro study of regional differences in the expression of markers during differentiation of hESC lines (LRB001-004), we noticed a distinct and direct transformation from undifferentiated OCT4 positive hESCs to SSEA1-positive fully differentiated epithelial cells (Laursen et al., 2007), and in a very recent investigation of six different LRB-cell lines we observed a similar abrupt transformation between OCT4-positive hESC regions and areas with either ectodermal p63-positive cells or neuroectodermal nestinpositive cells, while a direct transition into either meso- or endodermal marker positive cells, was not seen (Brøchner et al., 2011). In the present in vitro study we found an OCT4-postive 
epithelial-like cell type with a well-defined junctional complex facing the outside compartment which strongly resemble an in vivo embryonic epiblast cell type, whereas the pluripotent cells without junctional complexes in the central compartment of early cultures resemble an ICM-like cell type. The gradual pattern of differentiation from the center towards both apical and basal compartments indicates a direct shift from hESCs to columnar epithelial epiblast-like cells and to nestin-positive neuroectodermal cells in the basal compartment.

\section{Conclusion}

In conclusion, the epithelial coating of the colony might serve two different purposes: (1) The tight junction component of the junctional complex forms a barrier for transepithelial transport between the culture medium and the internal environment of the colony; thus the epithelial cells could provide cells in central and basal compartments with nutrients and other media components, probably via a specific receptor mediated transcellular epithelial transport, in order to create a microenvironment supporting the undifferentiated stage of underlying cells within the central compartment. (2) There seems to be a direct transformation of pluripotent hESCs into ecto- and neuroectodermal germ layer cells, while the adherens component of the junctional complex is instrumental in directing the further differentiation of hESCs into mesodermal and endodermal lineages via an epithelialmesenchymal transition (EMT).

\section{Acknowledgements}

The expert technical assistance of Sussi Forchhammer, Hanne Hadberg, Pernille S. Froh, Ha Nguyen (Department of Cellular and Molecular Medicine, The Panum Institute, University of Copenhagen, Copenhagen), Marjo Westerdahl (Laboratory of Reproductive Biology, Rigshospitalet, University Hospital of Copenhagen, Copenhagen), and Hanne Marie Mølbak Holm (Department of Basic Animal and Veterinary Sciences, Faculty of Life Sciences, University of Copenhagen) through all stages of the project is gratefully acknowledged. Keld B. Ottosen (Department of Cellular and Molecular Medicine, The Panum Institute, University of Copenhagen, Copenhagen) is thanked for the final layout of several figures.

\section{References}

Adewumi, O.; Aflatoonian, B.: Ahrlund-Richter, L.; Amit, M.; Andrews, P.W.; Beighton, G.; Bello, P.A.; Benvenisty, N.; Berry, L.S.; Bevan, S.; Blum, B.; Brooking, J.; Chen, K.G.; Choo, A.B.; Churchill, G.A.; Corbel, M.; Damjanov, I.; Draper, J.S.; Dvorak, P.; Emanuelsson, K.; Fleck, R.A.; Ford, A.; Gertow, K.; Gertsenstein, M.; Gokhale, P.J., Hamilton, R.S.; Hampl, A.; Healy, L.E.; Hovatta, O.; Hyllner,J.; Imreh, M.P.; Itskovitz-Eldor, J.; Jackson, J.; Johnson, J.L.; Jones, M.; Kee, K.; King, B.L.; Knowles, B.B.; Lako, M.; Lebrin, F.; Mallon, B.S.; Manning, D.; Mayshar, Y.; McKay, R.D.; Michalska, A.E.; Mikkola, M.; Mileikovsky, M.; Minger, S.L.; Moore, H.D.; Mummery, C.L.; Nagy, A.; Nakatsuji, N.; O'Brien, C.M.; Oh, S.K.; Olsson, C.; Otonkoski, T.; Park, K.Y.; Passier, R.; Patel, H.; Patel, M.; Pedersen, R.; Pera, M.F.; 
Piekarczyk, M.S.; Pera, R.A.; Reubinoff, B.E.; Robins, A.J.; Rossant, J.; Rugg-Gunn, P.; Schulz, T.C.; Semb, H.; Sherrer, E.S.; Siemen, H.; Stacey, G.N.; Stojkovic, M.; Suemori, H.; Szatkiewicz, J.; Turetsky, T.; Tuuri, T.; van den, B.S.; Vintersten, K.; Vuoristo, S.; Ward, D.; Weaver, T.A.; Young, L.A. \& Zhang, W. (2007). Characterization of human embryonic stem cell lines by the International Stem Cell Initiative. Nat. Biotechnol. 25, 803-816.

Brøchner, C.B.; Johansen, J.S.; Larsen, L.A.; Bak, M.; Mikkelsen, H.B.; Byskov, A.G.; Andersen, C.Y. \& Møllgård, K. (2011). YKL-40 is expressed in undifferentiated human embryonic stem cells and in cell progeny of all three germ layers with varying intensity (submitted)

Brøchner, C.B.; Vestentoft, P.S.; Lynnerup, N.; Andersen, C.Y. \& Møllgård, K. (2010). A twoand three-dimensional approach for visualizing human embryonic stem cell differentiation. Methods Mol Biol. 584, 179-93.

Hay, E.D. (2005). The mesenchymal cell, its role in the embryo, and the remarkable signaling mechanisms that create it. Dev. Dyn. 233:706-720.

Huettner, J.E.; Lu, A.; Qu, Y.; Wu, Y.; Kim, M. \& McDonald, J.W. (2006). Gap junctions and connexon hemichannels in human embryonic stem cells. Stem Cells 24, 16541667.

Hyttel, P. \& Madsen, I. (1987). Rapid method to prepare mammalian oocytes and embryos for transmission electron microscopy. Acta Anat. (Basel) 129, 12-14.

Johkura, K.; Cui, L.; Asanuma, K.; Okouchi, Y.; Ogiwara, N. \& Sasaki, K. (2004). Cytochemical and ultrastructural characterization of growing colonies of human embryonic stem cells. J. Anat. 205, 247-255.

Kalluri R. \& Weinberg R.A. (2009). The basics of epithelial-mesenchymal transition. J. Clin. Invest 119:1420-1428.

Kiprilov, E.N.; Awan, A.; Desprat, R.; Velho, M.; Clement, C.A.; Byskov, A.G.; Andersen, C.Y.; Satir, P.; Bouhassira, E.E.; Christensen, S.T. \& Hirsch, R.E. (2008). Human embryonic stem cells in culture possess primary cilia with hedgehog signaling machinery. J. Cell Biol. 180, 897-904.

Laursen, S.B.; Møllgård, K.; Olesen, C.; Oliveri, R.S.; Brøchner, C.B.; Byskov, A.G.; Andersen, A.N.; Hoyer, P.E.; Tommerup, N. \& Andersen, C.Y. (2007). Regional differences in expression of specific markers for human embryonic stem cells. Reprod. Biomed. Online. 15, 89-98.

Lo, C.W. \& Gilula, N.B. (1979). Gap junctional communication in the post-implantation mouse embryo. Cell 18, 411-422.

Reynolds, E.S. (1963). Liver parenchymal cell injury. I. Initial alterations of the cell following poisoning with carbon tetrachloride. J. Cell Biol. 19, 139-157.

Sathananthan, H.; Pera, M. \& Trounson, A. (2002). The fine structure of human embryonic stem cells. Reprod. Biomed. Online. 4, 56-61.

Thiery, J.P.; Acloque, H.; Huang, R.Y.J. \& Nieto, M.A. (2009) Epithelial-Mesenchymal Transitions in Development and Disease. Cell 139, 871-890.

Thomson, J.A.; Itskovitz-Eldor, J.; Shapiro, S.S.; Waknitz, M.A.; Swiergiel, J.J.; Marshall, V.S. \& Jones, J.M. (1998). Embryonic stem cell lines derived from human blastocysts. Science $282,1145-1147$. 
Ullmann, U.; In't, V.P.; Gilles, C.; Sermon, K.; De Rycke, M.; Van de Velde. H.; Van Steirteghem A. \& Liebaers, I. (2007). Epithelial mesenchymal transition process in human embryonic stem cells cultured in feeder-free conditions. Mol. Hum. Reprod. $13,21-32$. 


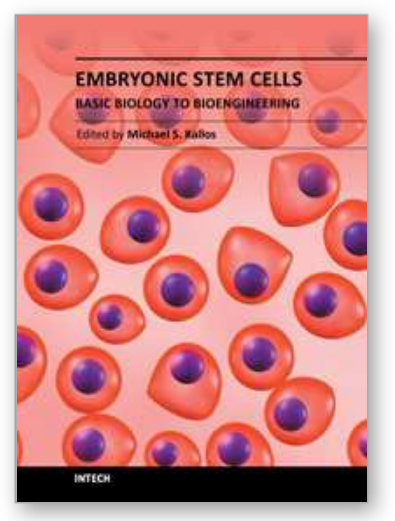

\author{
Embryonic Stem Cells - Basic Biology to Bioengineering \\ Edited by Prof. Michael Kallos
}

ISBN 978-953-307-278-4

Hard cover, 478 pages

Publisher InTech

Published online 15, September, 2011

Published in print edition September, 2011

Embryonic stem cells are one of the key building blocks of the emerging multidisciplinary field of regenerative medicine, and discoveries and new technology related to embryonic stem cells are being made at an ever increasing rate. This book provides a snapshot of some of the research occurring across a wide range of areas related to embryonic stem cells, including new methods, tools and technologies; new understandings about the molecular biology and pluripotency of these cells; as well as new uses for and sources of embryonic stem cells. The book will serve as a valuable resource for engineers, scientists, and clinicians as well as students in a wide range of disciplines.

\title{
How to reference
}

In order to correctly reference this scholarly work, feel free to copy and paste the following:

Janus Valentin Jacobsen, Claus Yding Andersen, Poul Hyttel and Kjeld Møllgård (2011). From Pluripotency to Early Differentiation of Human Embryonic Stem Cell Cultures Evaluated by Electron Microscopy and Immunohistochemistry, Embryonic Stem Cells - Basic Biology to Bioengineering, Prof. Michael Kallos (Ed.), ISBN: 978-953-307-278-4, InTech, Available from: http://www.intechopen.com/books/embryonic-stem-cellsbasic-biology-to-bioengineering/from-pluripotency-to-early-differentiation-of-human-embryonic-stem-cellcultures-evaluated-by-electr

\section{INTECH}

open science | open minds

\author{
InTech Europe \\ University Campus STeP Ri \\ Slavka Krautzeka 83/A \\ 51000 Rijeka, Croatia \\ Phone: +385 (51) 770447 \\ Fax: +385 (51) 686166 \\ www.intechopen.com
}

\author{
InTech China \\ Unit 405, Office Block, Hotel Equatorial Shanghai \\ No.65, Yan An Road (West), Shanghai, 200040, China \\ 中国上海市延安西路65号上海国际贵都大饭店办公楼 405 单元 \\ Phone: +86-21-62489820 \\ Fax: +86-21-62489821
}


(C) 2011 The Author(s). Licensee IntechOpen. This chapter is distributed under the terms of the Creative Commons Attribution-NonCommercialShareAlike-3.0 License, which permits use, distribution and reproduction for non-commercial purposes, provided the original is properly cited and derivative works building on this content are distributed under the same license. 